\title{
Assessment of psychological care in general practice
}

\author{
David Crossley, M Paul Myres, Greg Wilkinson
}

\begin{abstract}
Objective-To pilot a method of assessing psychological care by general practitioners.

Design-Prospective examination of psychological care given in general practice by using general health questionnaire with predetermined quantifiable and case specific indices of outcome established at the original consultation.
\end{abstract}

Setting-Rural general practice in Clwyd, North Wales.

Subjects-447 consecutive adult general practice attenders.

Main outcome measures-Three month follow up consultation rates, one year retrospective consultation rates, continuity of care, changes in general health questionnaire scores at follow up, general satisfaction, and acceptability of outcome measures.

Results-The principal and trainee identified 72 patients with psychological problems, 46 of whom had new conditions. 133 patients scored over 6 on the 28 item general health questionnaire, 33 of whom were identified as new cases by the general practitioners. 62 patients were seen at follow up, including 23 patients identified by the questionnaire but not by the doctor. The doctors used diagnostic terms to describe the presenting condition in 38 cases. At three month follow up the general health questionnaire scores had fallen by more than 5 points in $22 / 39$ patients identified and managed by doctors and $11 / 23$ identified by the questionnaire. The agreed index of good outcome was almost or completely achieved by 20 of the 39 patients managed by doctors.

Conclusion-Quantifiable methods of evaluating the quality of the structure, process, and outcome of psychological care can be achieved in general practice.

\section{Introduction}

Most patients with psychological problems are managed in primary care. ${ }^{1}$ Treatment patterns and rates of diagnosis vary widely and much of the variation cannot be accounted for by differences in practice populations. ${ }^{23}$ In particular, concern has been expressed about doctors' failure to detect hidden psychiatric morbidity in patients who present psychological distress in a somatic form. ${ }^{4}$

Few attempts at developing a method of assessing management of psychological illness in primary care have been published. Burton and Freeling audited diagnosis of depressive illness in general practice. ${ }^{5} \mathrm{~A}$ case definition satisfactory to all general practitioners was hard to establish and they found a large variation in rates of recognition of cases; all identified patients were given antidepressants.

For our study we generated data about the structure, process, and outcome of care using an inductive rather than a deductive model-one that focused on what general practitioners actually do (which may not necessarily mean starting from a research validated

\section{Resource card for psychological services}

- Available educational materials (booklets, tapes, etc)

- Non-NHS referral options (type, address, availability (appointment times, waiting list), what constitutes an appropriate referral):

Relate

Cruse

Drug agencies

Alcoholics Anonymous

Gamblers Anonymous, etc

- NHS referral options (type, address, availability (appointment times, waiting list), what constitutes an appropriate referral):

Community Psychiatric Nurse

Clinical Psychologist

Psychiatrist

Behaviour Therapist, etc

- Defined psychological assessment and treatment protocols

diagnosis) rather than on a theory about what they do. Thus our audit examined patients identified by a general practitioner's management decision rather than by diagnosis. This approach should include more cases and therefore more accurately represent the process of care. $^{\circ}$

The aims of the study were to identify the resources available for psychological care; to use structured methods of evaluating diagnosis and management within the consultation (using validated preconsultation questionnaires and management forms); and to develop ways of evaluating the outcome of management using predetermined defined measures.

\section{Subjects and methods}

The study took place in a rural practice in Clwyd comprising two full time principals and two part time job sharers. The list size was 4200 .

Resources for psychological care were identified and listed on a card for use in surgery (box). The list included educational materials and referral options (inside and outside of the NHS) with specific details concerning access to these referral points.

We asked 447 consecutive patients over the age of 16 attending one practitioner (MPM) and the trainee (DC) to complete a 28 item version of the general health questionnaire before the consultation. This questionnaire has been validated as a self reporting screening questionnaire and identifies patients with a high probability of psychological illness. ${ }^{7}$ Choice of cut off score alters the sensitivity and specificity of the questionnaire. ${ }^{8} \mathrm{~A}$ high sensitivity means that few true cases are missed but the false positive results are higher. We used a threshold of 6 , which Goldberg and Bridges found to give a sensitivity of $87 \%$ and specificity of $75 \%$ in one of the largest British validation studies. ${ }^{9}$

The general practitioners completed an assessment 
form for the patients without seeing the general health questionnaire score. This form (similar to ones used in previous studies ${ }^{+8}$ ) rated patients on two scales. The first classified the character of the presenting problem with five options: entirely physical, primarily physical with associated psychological problems, primarily psychological with associated physical problem, unrelated physical and psychological problems, or entirely psychological. The second six point scale concerned the severity of any accompanying psychological disturbance. The six options available on this scale included two "non-case" options (normal stable person with or without physical illness or person with subclinical emotional disturbance) and four "case" options (mild, moderate, or severe psychological disturbance, and conditions which would merit inpatient management).

If the doctor thought that the patient had a psychological problem relevant to the presenting condition which was severe enough to require management (the working definition of a case), a management form was filled out and filed in the notes. The form contained the identified problem (which might include a diagnosis), any relevant investigation, and a simple five point care plan. The care plan comprised a planned follow up, prescription, or referral or any combination of these. Some problems had been previously identified and were either being actively managed or had previously received attention. These were more likely to be detected by the principal than the trainee as he was more aware of past problems.

For each potential problem we decided on a quantifiable aspect that could be used as an index of outcome (table I). The outcome measure was noted on the management form. It could be negotiated with the patient and was assessed at the follow up interview in terms of the suitability of its choice (three point scale) and the degree of achievement (four point scale).

At three months we invited patients to return to the surgery (unless an earlier appointment had already been arranged) for interview. Three groups of patients were interviewed: those patients defined by both the general health questionnaire and the doctor as having a psychological problem $(n=33$, concurrent group); 30 patients who were defined by the general health questionnaire alone as having a psychological problem and chosen from the 78 high scoring patients by the toss of a coin (questionnaire group); and patients defined by the general practitioner alone as having a problem ( $n=13$, practitioner group).

We calculated the three month follow up consultation rate, one year retrospective consultation rate, and continuity score (assessing the number of times a patient reconsulted with the original doctor). Patients were asked to complete a second general health questionnaire form before the follow up interview and to answer questions on general satisfaction (on a four point scale) and agreement with their previous general health questionnaire score in the light of the doctor's original judgment (challenge question).

TABLE I-Possible outcome measures for assessing improvement in psychological problems

\begin{tabular}{|c|c|}
\hline Problem & Defined outcome in defined time \\
\hline Alcohol misuse & $\begin{array}{l}\text { Established controlled pattern of use } \\
\text { Diary of alcohol intake } \\
\text { Abstinence }\end{array}$ \\
\hline Insomnia & Quantifiable improved sleeping pattern \\
\hline Anxiety & $\begin{array}{l}\text { Improvement of somatic symptoms } \\
\text { Improved performance of tasks }\end{array}$ \\
\hline Phobia & Decreased avoidance \\
\hline Depressive symptoms & $\begin{array}{l}\text { Improved biological symptoms (for example, } \\
\text { weight gain) } \\
\text { Improved cognitive performance (for example, } \\
\text { on defined task) } \\
\text { Improved libido } \\
\text { Improved work performance }\end{array}$ \\
\hline
\end{tabular}

TABLE II-Number of patients with psychological problems detected by trainee and principal related to patients' score on general health questionnaire $(G H Q)$

\begin{tabular}{lrrrrrr}
\hline & Trainee & Principal & \multicolumn{3}{c}{ Total } \\
\hline No of new cases & & 23 & & 23 & & 46 \\
GHQ $<6$ & 7 & & 6 & & 13 & \\
GHQ $\geqslant 6$ & 16 & & 17 & & 33 & \\
No of cases previously detected & & 2 & & 24 & & 26 \\
GHQ $<6$ & 0 & & 14 & & 14 & \\
GHQ $\geqslant 6$ & 2 & & 10 & & 12 & \\
\hline
\end{tabular}

The challenge question was prefaced by an explanation that the general health questionnaire assesses the amount of upset and distress in someone's life at a given time. Patients in the concurrent group were asked whether they agreed with the joint conclusion of the general practitioner and questionnaire. Patients in the other two groups were informed that the doctor had expected their general health questionnaire score to be lower or higher after the original consultation and were asked: "Why do you think this was?"

\section{Results}

In all, 364 of the 477 attenders completed the general health questionnaire. Most of the shortfall was due to early and correctable administrative errors. Of the 76 patients in the follow up group, three had moved, one had died, and 10 did not reply to the letter asking them to attend for review. Thus follow up data were obtained on 62 patients $(82 \%)$.

A total of 133 patients had a general health questionnaire score of 6 or above. The general practitioners identified 72 patients with psychological problems, 26 of whom had been previously identified and managed (table II).

Each doctor identified 23 patients with new problems. The trainee was able to give a diagnosis for 19 patients and the principal for 20 . The trainee recorded eight cases of depression, four of chronic anxiety state, three alcohol misuse, two of bereavement reaction, one of acute stress reaction, and one of acute anxiety. The principal identified seven cases of depression, five of anxiety, four of mixed anxiety and depression, one of acute stress reaction, two of bereavement problems, and one of panic attacks. Diagnostic labelling was completely elusive for only one patient. Of the remaining patients who could not initially be diagnosed, three had relationship difficulties, one had personality problems, one had a fear of cancer, and one had prolonged fatigue.

The commonest initial management option for both doctors was to follow up without prescription. Indeed, in the six weeks only four patients were prescribed psychotropic drugs (one by the trainee, three by the principal) and only one was referred (to a behaviour therapist by the principal).

\section{OUTCOME}

Tables III and IV show the outcome for the three groups of patients. Patients identified by the principal were seen significantly more often (by any doctor) after identification $(p<0.005)$ compared with those identified by the trainee. The principal achieved greater continuity of care in the follow up period for all his patients. Continuity of care was also significantly better for the principal's managed patients (concurrent and practitioner groups) than for his unmanaged patients $(p<0.01)$. For the trainee, patients in the concurrent group had significantly better continuity of care than those in the questionnaire group $(p<0.025)$ but no significant difference was found for the practitioner group.

The annual consultation rate for patients in the concurrent group was higher than that for those in 


\begin{tabular}{|c|c|c|c|c|c|c|c|c|c|c|c|c|}
\hline \multirow[b]{2}{*}{ Group } & \multirow{2}{*}{$\begin{array}{l}\text { Total No } \\
\text { of patients }\end{array}$} & \multirow{2}{*}{$\begin{array}{c}\text { Mean (range) } \\
\text { age (years) }\end{array}$} & \multirow{2}{*}{$\begin{array}{l}\text { No seen at } \\
\text { follow up }\end{array}$} & \multirow{2}{*}{$\begin{array}{l}\text { Mean (range) } \\
\text { No of follow up } \\
\text { consultations }\end{array}$} & \multirow{2}{*}{$\begin{array}{l}\text { Continuity } \\
\text { score }\end{array}$} & \multirow{2}{*}{$\begin{array}{c}\text { Mean (range) } \\
\text { No of consultations } \\
\text { in past year }\end{array}$} & \multicolumn{4}{|c|}{ Degree of achievement of outcome } & \multicolumn{2}{|c|}{$\begin{array}{l}\text { Acceptability of outcome } \\
\text { measure selected }\end{array}$} \\
\hline & & & & & & & Nil & Slight & Almost & Complete & Improvable & Acceptable \\
\hline \multicolumn{13}{|l|}{ Trainee: } \\
\hline Concurrent & 16 & $41(17-72)$ & 15 & $2 \cdot 06(0-6)$ & $52 \%$ & $8 \cdot 19(1-22)$ & 4 & 3 & 3 & 5 & 2 & 13 \\
\hline Questionnaire & 15 & $39(18-61)$ & 12 & $2 \cdot 71(0-9)$ & $16 \%$ & $6 \cdot 1+(0-20)$ & & & & & & \\
\hline Practitioner & 7 & $43(26-68)$ & 3 & $1.00(0-2)$ & $0 \%$ & $3 \cdot 1+(1-6)$ & & 2 & & 1 & 1 & 2 \\
\hline \multicolumn{13}{|l|}{ Principal: } \\
\hline Concurrent & 17 & $50(30-71)$ & 15 & $3 \cdot 47(0-9)$ & $71 \%$ & $9 \cdot 06(1-33)$ & 3 & 5 & 3 & 4 & 5 & 10 \\
\hline Questionnaire & 15 & $53(17-84)$ & 11 & $2 \cdot 67(0-9)$ & $45 \%$ & $5 \cdot 2(0-12)$ & & & & & & \\
\hline Practitioner & 6 & $57(22-75)$ & 6 & $3 \cdot 30(2-9)$ & $55 \%$ & $10 \cdot 2(3-18)$ & 2 & & 3 & 1 & 2 & 4 \\
\hline
\end{tabular}

TABLE IV-Outcome data on patients with psychological problems according to practitioner and general health questionnaire, questionnaire only, and practitioner only

\begin{tabular}{|c|c|c|c|c|c|c|c|c|c|}
\hline & \multicolumn{4}{|c|}{ General health questionnaire score at 3 month follow up } & \multicolumn{5}{|c|}{ Satisfaction rating } \\
\hline & Increased & Same & Decreased by $\geqslant 3$ & Decreased by $\geqslant 5$ & None & Little & Fair & Complete & No response \\
\hline \multicolumn{10}{|l|}{ Trainee: } \\
\hline Concurrent $(n=15)$ & 1 & & 12 & 11 & 1 & & 3 & 10 & 1 \\
\hline Questionnaire $(n=12)$ & 1 & 1 & 8 & 7 & & 1 & 3 & 5 & 3 \\
\hline Practitioner $(n=3)$ & & 1 & 2 & 0 & & & & 3 & \\
\hline \multicolumn{10}{|l|}{ Principal: } \\
\hline Concurrent $(n=15)$ & 3 & & 12 & 11 & & 2 & 5 & 7 & 1 \\
\hline Questionnaire $(n=11)$ & 1 & & 7 & 4 & & 1 & & 9 & $i$ \\
\hline Practitioner $(n=6)$ & 4 & 0 & 1 & 0 & & & 1 & 4 & 1 \\
\hline
\end{tabular}

the questionnaire group, but the difference was not significant.

The outcome measure chosen at the initial consultation was thought acceptable by most patients and the measure was judged to have been almost or completely achieved in about half of patients in the concurrent group at three month follow up.

Nearly all patients in the concurrent group (28/30) acknowledged that the judgment of the general health questionnaire and doctor was correct. Twenty two of the 23 patients in the questionnaire group acknowledged that psychological distress had contributed to their high general health questionnaire scores, suggesting that the doctor's judgment was incorrect by this standard. There was less consensus in the managed but low scoring group; even so, seven of the nine patients acknowledged that there was a high degree of psychological distress that they had not revealed on the general health questionnaire but had disclosed to the doctor.

More patients in the concurrent group than the questionnaire group (unmanaged) hac a reduction in general health questionnaire score of 5 points or more at follow up, but this finding was significant only in the trainee's patients ( $p<0.05$, table IV). In the practitioner group the scores of the trainee's patients changed little and those of the principal's patients rose slightly.

\section{PATIENT SATISFACTION}

A high level of satisfaction was recorded: over $80 \%$ of patients who answered this anonymous written question said that they were reasonably or completely satisfied with the care they had been given for the problem they originally consulted with by the doctor they first saw (table IV). No significant differences were found between doctor or patient groups. Eight patients did not endorse any of the four options open to them.

\section{Discussion}

Examination of resources available for psychological problems is relatively easy and helps to identify deficiencies and management options. Most surgeries have educational resources to hand and taking a little - time to tabulate them as an aide-memoire for the surgery helps ensure that the doctor keeps them.
The general health questionnaire has already been validated in general practice as a measure of psychological problems and is useful for determining missed cases in an assessment of effectiveness of psychological care. The number of missed cases depends on the threshold score used in the questionnaire but ultimately the judgment must lie with the general practitioner. There may be a subgroup of "missed" patients who would not wish to be labelled psychologically ill, preferring to receive treatment for their physical complaints. ${ }^{10}$ Almost half of the patients who scored 6 or over on the general health questionnaire at follow up and had not been identified initially by the practitioners subsequently received some form of psychological management, and the general health questionnaire had played a part in their detection.

The probable prevalence of psychological illness (the proportion of patients who obtain a high score on the general health questionnaire after a correction term has been applied) was similar in our study $(40.0 \%)$ to that reported for patients in Lewisham $(39.6 \%)^{11}$ and Manchester $(42.9 \%){ }^{3}$ Furthermore, the trainee saw and identified comparable numbers of general health questionnaire validated cases as the principal.

\section{OUTCOME}

Over $80 \%$ of the outcome group were seen. Most patients were seen at follow up by the doctor they originally consulted with, but a few could not be interviewed and responded by postal questionnaire. Cross over interviewing was considered (to reduce reporting bias) but the immediate educational benefit of seeing what had happened to our own patients and the fact that they would be more likely to return to the original doctor weighed against this.

Interestingly, the unmanaged patients (questionnaire group) were significantly more difficult to follow up. These patients may have had least to gain from reinterview or may not have wished to disclose psychological problems - you may have a sore throat and be bereaved but you may only want the general practitioner to sort out your pharyngitis.

PSYCHIATRIC DIAGNOSTIC TERMS

The initial definition of the problem did not include an ICD diagnosis in seven patients. This confirms the view that in general practice a diagnosis does not 
always initiate care but may evolve during the management process. ${ }^{112}$

There is justifiable uncertainty in the use of diagnostic terms even among psychiatrists ${ }^{13}$ and there is more educational value in the first instance in performing a retrospective analysis of cases defined by peer review than by artificially preestablishing theoretical case criteria and imposing this on future observed practice.

Differing patterns of diagnostic use emerged. Only the trainee identified alcohol misuse (three cases) and only the principal diagnosed mixed anxiety and depression (four cases). Of course, the principal and trainee might have attracted different kinds of patients.

\section{HIGH CONSULTERS}

Three out of four patients in the managed groups had higher consultation rates than the average practice rate in the previous year-especially those in the concurrent group whose mean consultation rate was two and a half times more than the overall practice mean rate (3.41 including non-consulters).

Arguably, case recognition could be described as a function of high consultation rate rather than the other way round, but even the unmanaged patients (questionnaire group) had higher rates of consultation than the practice as a whole. Wright found that unrecognised mental distress was associated with high consultation rates in patients with chronic physical illness. ${ }^{12}$

\section{UNMANAGED PATIENTS}

The practice does not have personalised lists, and access to any given doctor is not difficult. The lower continuity scores for the unmanaged questionnaire group compared with the managed concurrent group may reflect the active management of the concurrent group or an implied criticism of the doctor's response in patients in the questionnaire group.

The fall in general health questionnaire scores at follow up may not necessarily be a result of effective management but may have a statistical basis (that is, regression to the mean). The comparison is not strictly valid as patients in the questionnaire group were not detected by the doctor and so were not true controls.

\section{CHALLENGE QUESTION}

As expected, nearly all patients identified by both general health questionnaire and doctor agreed that their psychological problems played an important part in their initial presentation. The fact that management plans and, possibly, mutually agreed outcome measures had been set up at that stage confirmed this view.

Nearly all the patients in the unmanaged group acknowledged the validity of the general health questionnaire score. Often recent life events accounted for the score (recent surgery (4 patients), pregnancy problems (2), work problems (3), family disputes (3)) but other patients accounted for it in terms of the physical complaints they had had at the time (all presented with physical problems).

Patients in the practitioner group were more likely to disagree with the general health questionnaire score, with seven admitting to not disclosing a psychological problem in the questionnaire. There may also have been recording bias (in wanting to agree with the doctor) and numbers were small (nine cases in total).

\section{TREATMENT PATTERNS}

Only four patients were prescribed psychotropic drugs for the first time. Unfortunately, comparison of new prescriptions with the same period in the previous year was not possible with prescribing, analysis, and cost data (PACT), although the NHS referral rate for that period for the principal was the same.

Of the 15 patients with depression, only three started treatment with antidepressants. This may not reflect the severity of depression but our preference for non-pharmacological therapy. The seven general practitioners studied by Burton and Freeling prescribed antidepressants to all identified patients. ${ }^{5}$

\section{OUTCOME MEASURES}

In his review of outcome measurement in general practice, Metcalfe notes: "in general practice and especially in the care of chronic and psychiatric illness, the objectives and therefore the measurements of outcome must be management orientated and patient centred." "'14

There was a high degree of satisfaction with the outcome measures chosen. If the measures were mutually agreed between patient and doctor they offered preset goals that could be used as a yardstick in recovery. Although the measures were initially quite difficult to determine, as the study proceeded greater skill was built up in choosing quantifiable aspects of psychological dysfunction.

\section{CONCLUSION}

Assessment of psychological care is feasible despite the difficulties in establishing a consensus on standardised diagnostic terms and optimum management. Before genuine debate about these issues can take place information is needed about current practice and what happens to people needing some form of psychological management. Our simple form of assessment attempts to avoid getting stuck in an unhelpful debate about prospective diagnostic criteria by using nationally validated techniques of preconsultation inquiry (the general health questionnaire) and a quantifiable, case specific index of good outcome.

What are the benefits of the assessment? As a result of our study we have identified deficiencies in resources - for example, the absence of protocols. We have examined fundamental issues of process-the suboptimal detection rate, the low prescribing rate, the need to predict a defined outcome for a defined intervention - and we have obtained a lot of data on outcome that has influenced future management. The practice's awareness of psychological issues has been raised and all the doctors in the practice have been encouraged to examine their knowledge and skills relating to psychological care. Analysis and discussion have prompted new approaches to management.

We thank the Institute of Health Studies, Wrexham, Clwyd, for its help.

1 Wilkinson G. I don't want you to see a psychiatrist. BMF 1988;297:1144-5.

2 Marks JN, Goldberg DP, Hillier JF. Determinants of the ability of general practitioners to detect psychiatric illness. Psychol Med 1979;9:337-53.

3 Goldberg DP, Bridges K. Screening for psychiatric illness in general practice: the general practitioner versus the screening questionnaire. $f R$ Coll Gen the general practition

4 Wright AF. A study of the presentation of somatic symptoms in general practice by patients with psychiatric disturbance. $B r \mathcal{F}$ Gen Pract 1990;40: 459-63.

5 Burton RH, Freeling P. How general practitioners manage depressive illness: developing a method of audit. $\mathcal{F} R$ Coll Gen Pract 1982;32:558-61

6 Kraupl-Taylor F. The concepts of disease. Psychol Med 1980;10:419-24.

Wright AF, Perini AF. Hidden psychiatric illness: use of the general health questionnaire in general practice. $\mathcal{F} R$ Coll Gen Pract 1987;37:164-7.

8 Wilkinson G, Markus AC. Validation of a computerised assessment (PROQSY) of minor psychological morbidity by relative operating characteristic of minor psychological morbidity by relative operating characteristic
analysis using a single GP's assessments as criterion measures. Psychol Med

9 Goldberg DP, Williams P. A user's guide to the general health questionnaire. Windsor: NFER Nelson, 1988 .

10 Boardman AP. The general health questionnaire and the detection of Boardman AP. The general health questionnaire and the detection of
emotional disorder by general practitioners. Br $\mathcal{F}$ Psychiatry 1987;151: emotional disorder by general practitioners. Br J Psychiatry 1987;15

11 Howie JRG. Diagnosis--the Achilles heel? I R Coll Gen Pract 1972;22:310-5.

2 Wright AF. Psychological distress: outcome and consultation rates in one general practice. I R Coll Gen Pract 1988;38:542-5.

13 Shepherd M, Wilkinson G. Primary care as the middle ground for psychiatric epidemiology. Psychol Med 1988;18:263-7.

14 Metcalfe DHH. Measurement of outcomes in general practice. In: Hopkins A, Costain D, eds. Measuring the outcomes of medical care. London: Royal College of Physicians, 1990:95.

(Accepted 2 October 1992) 